\title{
Selective Electrochemical Nitrogen Reduction Driven by Hydrogen Bond Interactions at Metal-Ionic Liquid Interfaces
}

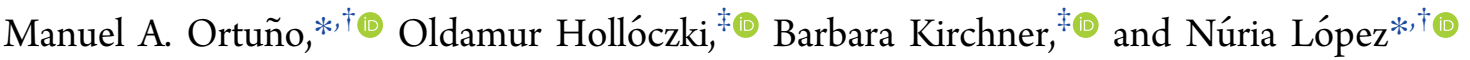 \\ ${ }^{\dagger}$ Institute of Chemical Research of Catalonia (ICIQ) and Barcelona Institute of Science and Technology (BIST), Av. Països \\ Catalans 16, 43007 Tarragona, Spain \\ ${ }^{\ddagger}$ Institut für Physikalische und Theoretische, Universität Bonn, Mulliken Center for Theoretical Chemistry, Beringstrasse 4-6, \\ 53115 Bonn, Germany
}

Supporting Information

\begin{abstract}
Increasing the activity of the nitrogen reduction reaction while slowing the detrimental hydrogen evolution reaction is a key challenge in current electrocatalysis to provide a sustainable route to ammonia. Recently, nanoparticles in ionic liquid (IL) environments have been found to boost the selectivity of electrochemical synthesis of ammonia from dinitrogen at room temperature. Here, we use for the first time a fully atomistic representation of metal-IL interfaces at the density functional theory level to understand experimental evidence, with particular focus on the rate and selectivity determining formation of $\mathrm{N}_{2} \mathrm{H}$ intermediates compared to hydrogen evolution. We find that decorating the metal surface with fluorinated ILs creates specific $\mathrm{H}$-bond interactions between $\mathrm{Ru}-\mathrm{N}_{2} \mathrm{H}$ and IL anions, stabilizing this intermediate and thus driving the selectivity of the electrochemical process.
\end{abstract}

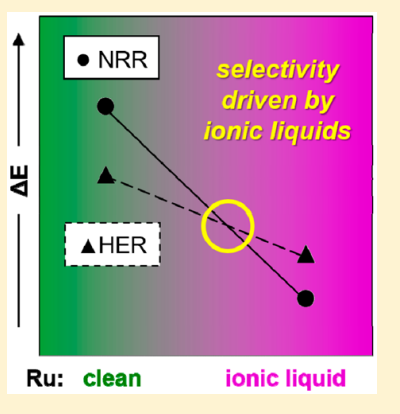

\begin{abstract}
mmonia synthesis, one of the most important processes in A the chemical industry, keeps the supply of fertilizers and related $\mathrm{N}$-containing chemicals worldwide. The Haber-Bosch process, which involves the thermally driven hydrogenation of $\mathrm{N}_{2}$ under harsh pressure and temperature conditions, produces 500 million tons of $\mathrm{NH}_{3}$ per year and consumes ca. $1 \%$ of the global energy. ${ }^{1}$ Transition from Haber-Bosch to less energydemanding processes is a major goal in chemistry. ${ }^{2,3}$

Mimicking the gentle reaction conditions found in enzymes, electrocatalysis is a promising alternative to achieve the nitrogen reduction reaction (NRR) at low temperature. ${ }^{4-6}$ The challenge is promoting the NRR while shutting down the competing hydrogen evolution reaction (HER) that reduces the efficiency of the process. ${ }^{7}$ However, the rational design of new only metal-based catalysts with enhanced selectivity is limited by how the stabilities of certain intermediates are dependent on each other, in other words, by linear scaling relationships. $^{8,9}$
\end{abstract}

Experimental efforts have boosted Faradaic efficiencies by working in a molten hydroxide suspension at high temperature $^{10}$ and supporting $\mathrm{Au}$ nanoparticles on $\mathrm{CeO}_{x}$-reduced graphite oxide. ${ }^{11}$ Quite recently, MacFarlane and coworkers reported Fe-based catalysts with a Faradaic efficiency of $32 \%{ }^{12}$ and $60 \%{ }^{13}$ when using fluorinated ionic liquids (ILs). Besides the relatively higher solubility of $\mathrm{N}_{2}$ in ILs, ${ }^{14}$ the specific role of ILs on the selective NRR is not fully understood. To shed light into these features, we turn to theoretical methods. ${ }^{15}$

Herein, we employed density functional theory (DFT) to gain mechanistic insight on IL-decorated metal surfaces ${ }^{16}$ for the electrochemical reduction of $\mathrm{N}_{2}$ to $\mathrm{NH}_{3}$ (Figure 1a). Such metal-IL interfaces have the potential to circumvent linear scaling relationships, which opens the path to enhanced NRR (a)

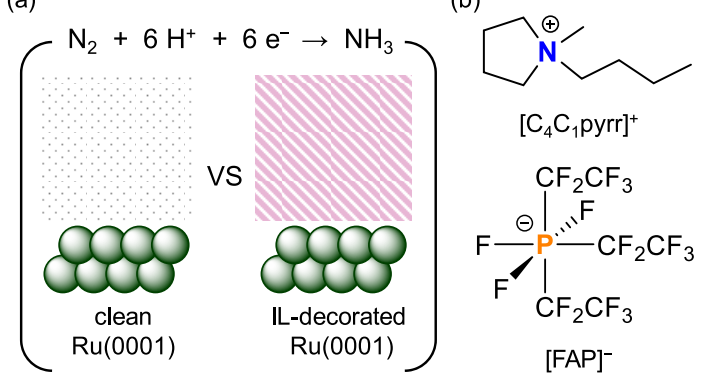

Figure 1. (a) Ru-catalyzed electrochemical nitrogen reduction reaction on clean (dotted square) and IL-decorated (striped square) surfaces. (b) $\mathrm{N}$-Butyl- $\mathrm{N}$-methylpyrrolidinium $\left[\mathrm{C}_{4} \mathrm{C}_{1} \text { pyrr }\right]^{+}$and tris(perfluoroethyl)-trifluorophosphate $[\mathrm{FAP}]^{-}$under study.

selectivity. We modeled a Ru-based catalyst, as studied in literature, ${ }^{17}$ and the IL $\left[\mathrm{C}_{4} \mathrm{C}_{1}\right.$ pyrr $][\mathrm{FAP}]$ (Figure $1 \mathrm{~b}$ ), as reported experimentally. ${ }^{13}$ Computational studies on bulk ILs have been extensively reported, ${ }^{18}$ but due to its complexity, less attention has been paid to their interface with solids. ${ }^{19,20}$ Pádua and coworkers ${ }^{21}$ parametrized metal-IL interactions to study the solvation of $\mathrm{Ru}$ nanoparticles, and Heinz et al. ${ }^{22}$ performed classical molecular dynamics (MD) simulations on $\mathrm{Au}-\mathrm{IL}$ structures. To the best of our knowledge, this is the first fully atomistic study of a bulk IL on a transition metal surface at DFT level that directly addresses reactivity. 
First, to evaluate the dynamic behavior of the fluorinated IL at hand, we described the liquid phase of the pure $\mathrm{IL}^{23} \mathrm{~N}_{2} @$ IL, and $\mathrm{NH}_{3} @ \mathrm{IL}$ by means of classical MD simulations. We used a cubic box with 240 IL pairs to model the bulk phase (Figure 2a). For $\mathrm{N}_{2} @ \mathrm{IL}$ and $\mathrm{NH}_{3} @ \mathrm{IL}$, we included one $\mathrm{N}_{2}$ or

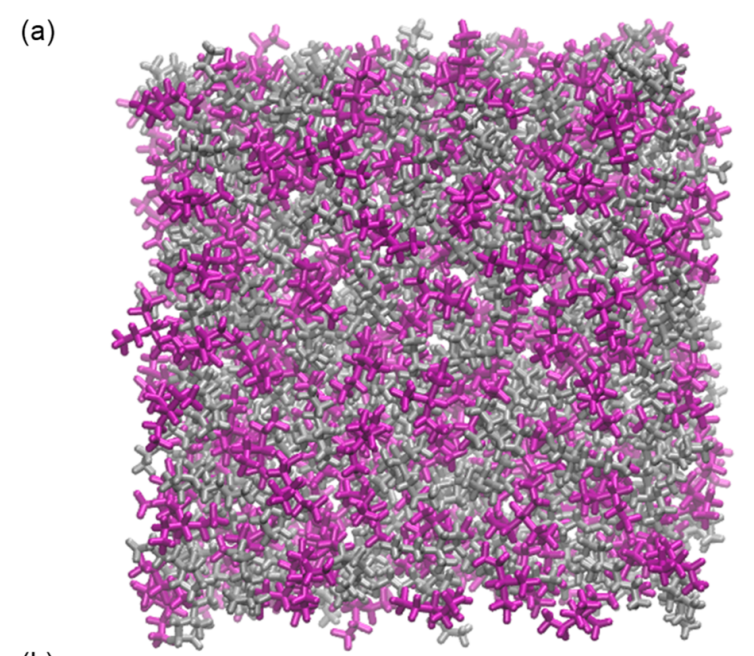

(b)

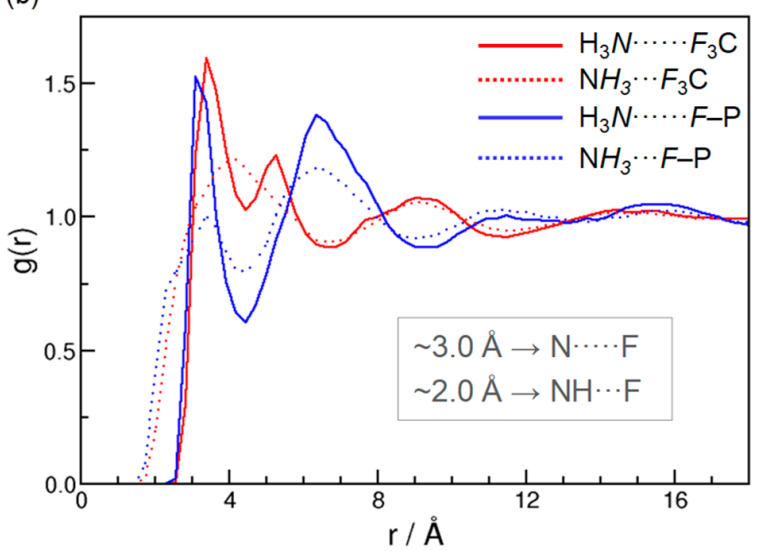

Figure 2. Classical MD simulations. (a) Cubic box containing $240 \mathrm{IL}$ pairs (cations in gray, anions in purple) and (b) corresponding RDFs for the $\mathrm{NH}_{3} @ \mathrm{IL}$ simulation, highlighting contacts between the $\mathrm{H}$ atoms of $\mathrm{NH}_{3}$ and the $\mathrm{F}$ atoms of $[\mathrm{FAP}]^{-}$.

one $\mathrm{NH}_{3}$ molecule per simulation box, respectively. Radial distribution function (RDF) data, which show probable atomatom distances, can be consulted in Figures $\mathrm{S} 2-4$ for all three simulations. RDF data for the $\mathrm{N}_{2} @ \mathrm{IL}$ simulation (Figure S3) show significant contact between $\mathrm{N}_{2}$ and the methyl $\mathrm{C}$ atom of the butyl chain of $\left[\mathrm{C}_{4} \mathrm{C}_{1} \text { pyrr }\right]^{+}$, suggesting that $\mathrm{N}_{2}$ might be mainly in the nonpolar microphase. The most relevant $\mathrm{RDF}$ data for the $\mathrm{NH}_{3} @ \mathrm{IL}$ simulation are summarized in Figure $2 \mathrm{~b}$. At $\sim 3 \AA$, one can observe interplays between the $\mathrm{N}$ atom of $\mathrm{NH}_{3}$ and (i) the $\mathrm{F}$ atoms of the $\mathrm{CF}_{3}$ groups $\left(F-\mathrm{CF}_{2}\right)$ in $[\mathrm{FAP}]^{-}$anions (solid red line) and (ii) the $\mathrm{F}$ atoms directly attached to $\mathrm{P}(\mathrm{F}-\mathrm{P})$ in $[\mathrm{FAP}]^{-}$anions (solid blue line). Concurrently, some interactions can be detected starting at $\sim 2$ $\AA$ between the $\mathrm{H}$ atoms of $\mathrm{NH}_{3}$ and $\mathrm{F}-\mathrm{CF}_{2}$ and $\mathrm{F}-\mathrm{P}$ atoms (dashed red and blue lines, respectively). The occasional close approach of the $\mathrm{H}$ and $\mathrm{F}$ atoms results in a shoulder on the $\mathrm{RDF}$ and points to the possibility of a weak H-bond interaction between $\mathrm{NH}_{3}$ and $[\mathrm{FAP}]^{-}$. The interactions between the $\mathrm{N}$ atom and the inner $\mathrm{F}-\mathrm{CF}$ atoms are less marked than those involving the more accessible $\mathrm{F}-\mathrm{CF}_{2}$ and $\mathrm{F}-\mathrm{P}$ atoms (Figure S4). Additional RDF data from classical and first-principles MD simulations with $24 \mathrm{IL}$ pairs can be consulted in Figures S5-6.

Next, we explored the interface between the Ru catalyst and the IL. For that purpose, we designed a 3-layer $\mathrm{p}(6 \times 6)$ $\mathrm{Ru}(0001)$ slab with $8 \mathrm{IL}$ pairs equilibrated through classical and first-principles MD simulations. The use of isolated IL pairs would not capture the bulk effect of the liquid; likewise, continuum methods would not describe explicit interactions between solute and solvent. The aim here is to describe the IL as a bulk liquid rather than as isolated pair clusters. The final structure after equilibration is shown in Figure 3a. Close (a)

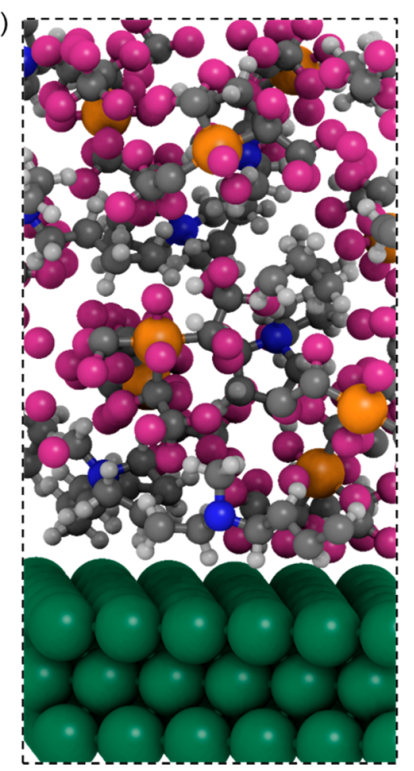

(b)
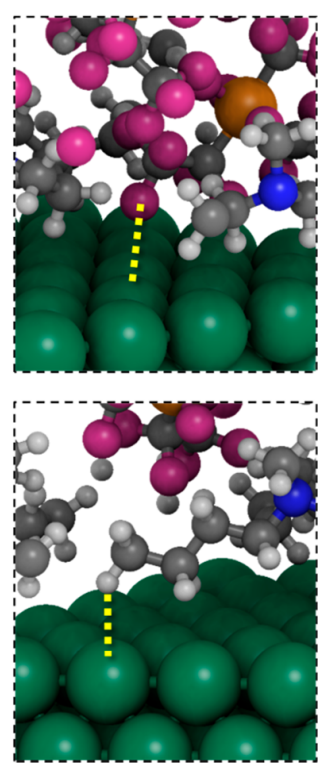

Figure 3. First-principles MD simulations. (a) Repeating unit cell of the interface formed by a 3-layer $\mathrm{p}(6 \times 6) \mathrm{Ru}(0001)$ slab with $8 \mathrm{IL}$ pairs (548 atoms) and (b) zoom-in insets highlighting $\mathrm{Ru} \cdots \mathrm{F}$ (top) and $\mathrm{Ru} \cdots \mathrm{H}$ (bottom) close contacts. Legend: Ru (green), P (orange), F (pink), N (blue), C (gray), H (white).

contacts between the $\mathrm{Ru}$ surface and the $\mathrm{F}-\mathrm{CF}_{2}$ group in $[\mathrm{FAP}]^{-}(\mathrm{Ru} \cdots \mathrm{F}$ distance of $3.026 \AA)$ and the $\mathrm{H}-\mathrm{CH}_{2}$ group of the butyl chain in $\left[\mathrm{C}_{4} \mathrm{C}_{1} \text { pyrr }\right]^{+}(\mathrm{Ru} \cdots \mathrm{H}$ distance of $2.363 \AA)$ are depicted in Figure $3 \mathrm{~b}$.

With an atomistic representation of the clean metal and the metal-IL interface at hand, we next evaluated the potential energy surface of the nitrogen reduction and hydrogen evolution reactions at DFT level. Species involving the clean surface are denoted with A-E. The corresponding ILdecorated counterparts follow the same nomenclature and add the prefix IL. Due to the rich chemical composition of the interface (Figure $3 b$ ), we found several configurations for each intermediate, but only the most stable ones are reported here. The explicit representation of the solvent on clean metal surfaces $^{24}$ is out of the scope of the present work, which rather focuses on the selectivity induced by ILs.

Guided by previous computational studies on $\mathrm{Ru}$ catalysts, ${ }^{8,25-27}$ we focused on the adsorption of $\mathrm{N}_{2}$ and formation of the $\mathrm{N}_{2} \mathrm{H}$ intermediate, a key rate- and selectivitydetermining step (additional intermediates can be consulted in Table S1) and also computed the competitive hydrogen 
evolution to address selectivity (Figure $4 a$ ). Figure $4 \mathrm{~b}$ displays the relative electronic energies of key intermediates during

(a) $\mathrm{N}_{2}{ }^{*}+\mathrm{H} \rightarrow \mathrm{N}_{2} \mathrm{H}^{*}$ (NRR) vs $\mathrm{H}^{*}+\mathrm{H} \rightarrow \mathrm{H}_{2}{ }^{*}(\mathrm{HER})$

(b)
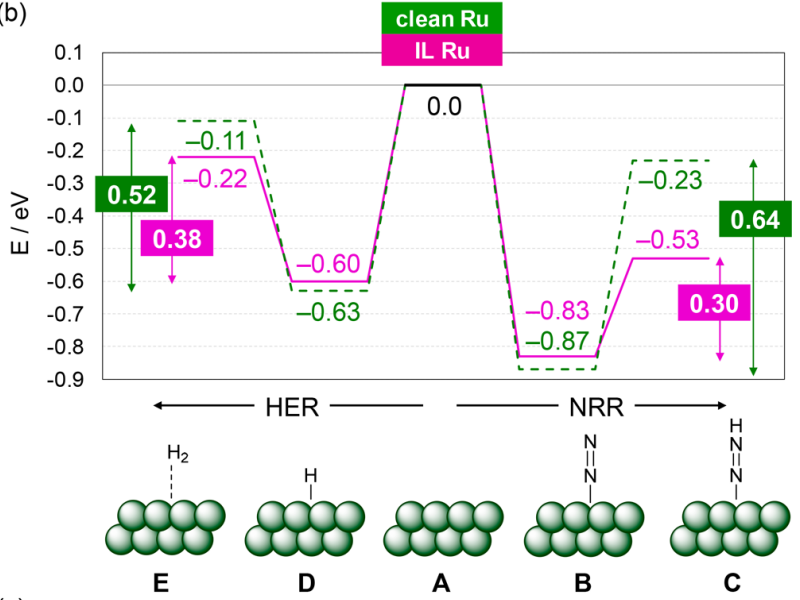

(c)

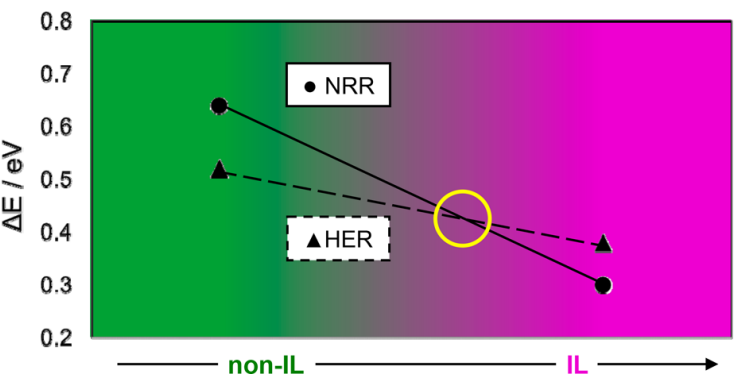

Figure 4. (a) Rate and selectivity determining step comparison studied herein and (b) corresponding reaction energy profiles of such intermediates during NRR (right) and HER (left) for clean (dashed green line) and IL-decorated (solid purple line) Ru surfaces. (c) Relative energy differences for NRR (circles) and HER (triangles) according to the absence (green) and presence (purple) of IL. The change of selectivity from HER to NRR is indicated with a yellow circle. Lines (solid for NRR, dashed for HER) serve as a guide to the eye.

NRR (right side) and HER (left side). On the one hand, the dashed green line shows the energy values for the clean $\mathrm{Ru}$ surfaces. The end-on adsorption of $\mathrm{N}_{2}$ on $\mathbf{A}$ giving rise to $\mathbf{B}$ is exothermic by $0.87 \mathrm{eV}$ (the side-on adsorption is only $0.23 \mathrm{eV}$ downhill). Subsequent formation of the $\mathrm{N}_{2} \mathrm{H}$ intermediate $\mathrm{C}$ demands $0.64 \mathrm{eV}$ above $\mathbf{B}$. Regarding HER, the reaction from D, adsorbed $\mathrm{H}$, to $\mathrm{E}$, physisorbed $\mathrm{H}_{2}$, requires $0.52 \mathrm{eV}$. The lower relative energy of HER $(0.52 \mathrm{eV})$ compared to that of NRR $(0.64 \mathrm{eV})$ explains the low selectivity toward ammonia observed for pure metal catalysts. On the other hand, the solid purple line shows the energy values for the IL-decorated $\mathrm{Ru}$ surfaces. The end-on adsorption of $\mathrm{N}_{2}$ on IL-A to form IL-B is also exothermic by $0.83 \mathrm{eV}$ (the side-on adsorption is only 0.20 $\mathrm{eV}$ downhill), suggesting that the IL surroundings play a small role at this stage. However, the formation of the $\mathrm{N}_{2} \mathrm{H}$ intermediate IL-C is significantly favored, requiring only 0.30 $\mathrm{eV}$ comapred to $0.64 \mathrm{eV}$ for the clean surface. As for HER, the $\mathrm{H}_{2}$ formation from IL-D to IL-E demands $0.38 \mathrm{eV}$. This value is lower than that for HER with the clean surface, $0.52 \mathrm{eV}$, but slightly higher than that for NRR with the IL-decorated surface, $0.30 \mathrm{eV}$. These results show that the IL environment increases both the activity (by stabilizing IL-C compared to C) and selectivity (by stabilizing IL-C compared to IL-E). Such effect is better displayed in Figure 4c, which represents how the selectivity to HER for the non-IL system (left) switches to NRR in the presence of IL (right). The effect of the IL on selectivity remains the same when considering zero point vibrational energy corrections and Gibbs energies (Table S3).

The above-mentioned results can be explained by looking at the atomic structure of the $\mathrm{N}_{2} \mathrm{H}$ intermediate in Figure 5a. (a)

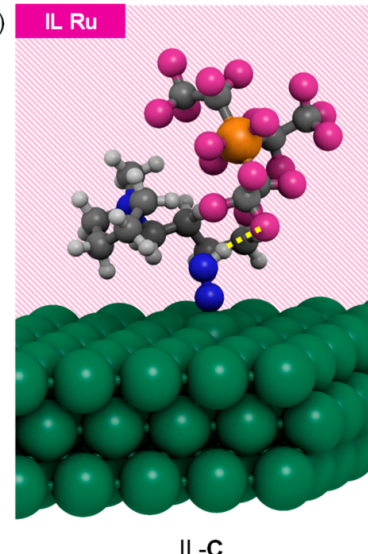

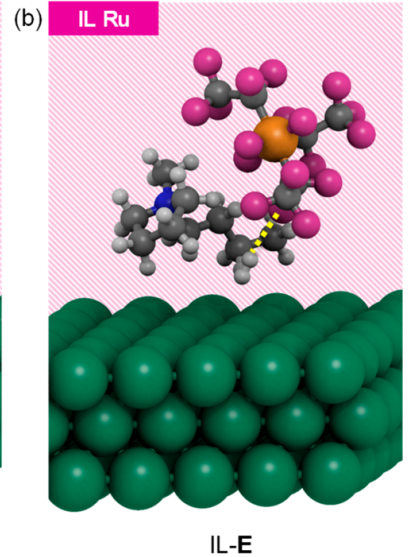

Figure 5. DFT-optimized structures of (a) the $\mathrm{N}_{2} \mathrm{H}$ intermediate, IL$\mathrm{C}$, and (b) the $\mathrm{H}_{2}$ intermediate, IL-E, both including an IL configuration coming from the metal-IL MD simulations. Selected ILs are omitted for clarity. The yellow dashed lines highlight $\mathrm{H} \cdots \mathrm{F}$ interactions. Legend: Ru (green), P (orange), F (pink), N (blue), C (gray), $\mathrm{H}$ (white).

Compared to the Ru-only surface C, IL-C exhibits a clear interaction between the $\mathrm{N}_{2} \mathrm{H}$ group and the $\mathrm{F}-\mathrm{CF}_{2}$ atom in $[\mathrm{FAP}]^{-}$. The $\mathrm{H} \cdots \mathrm{F}$ and $\mathrm{N} \cdots \mathrm{F}$ distances of 1.865 and $2.871 \AA$, respectively, evoke the patterns found in the liquid $\mathrm{NH}_{3} @ \mathrm{IL}$ simulation (Figure 2b). Likewise, similar contacts might also be at work on $\mathrm{N}_{2} \mathrm{H}_{x}$ species ${ }^{28}$ or dissociative mechanisms involving $\mathrm{NH}_{x}$ intermediates. ${ }^{25-27}$ Binding energies of ca. 0.1 $\mathrm{eV}$ have been estimated for related contacts involving $\mathrm{CH}_{3} \mathrm{OH}$ and $\mathrm{CH}_{3} \mathrm{CF}_{3}{ }^{29}$ Our relative $\Delta E$ of $0.34 \mathrm{eV}$ between $\mathbf{B}$ and $\mathbf{C}$ $(0.64 \mathrm{eV})$ and IL-B and IL-C $(0.30 \mathrm{eV})$ suggests that this interaction alone might not be responsible for the stabilization and that the inherently charged bulk IL environment has an additional electrostatic effect ${ }^{30-32}$ and should not be ignored in the modeling. As for the competing HER, the $\mathrm{H}_{2}$ intermediate IL-E is shown in Figure 5b. The interaction between the nonpolar $\mathrm{H}_{2}$ and $\mathrm{F}$ atoms is weaker $(\mathrm{H} \cdots \mathrm{F}$ distance of $2.471 \AA$ ), and thus, the stabilization is less marked compared to $\mathrm{N}_{2} \mathrm{H}$ species. Overall, $\mathrm{H} \cdots \mathrm{F}$ interactions in ILcontaining NRR intermediates boost the selectivity of the process, in line with recent experiments. ${ }^{13}$

With respect to the role of reactant water, it has been shown that (i) the $\mathrm{OH}$ groups of hexafluoroisopropanol cluster together, forming polar domains, and are separated from the fluorine-based groups, ${ }^{33}$ and (ii) $\mathrm{NH}$-based species with a free lone pair interact with water as $\mathrm{H}$-bond acceptors rather than $\mathrm{H}$-bond donors. This suggests that $\mathrm{N}_{2} \mathrm{H} \cdots \mathrm{F}$ interactions, in which $\mathrm{N}_{2} \mathrm{H}$ acts as $\mathrm{H}$-bond donor (Figure 5a), will be probably not disturbed. In agreement with this discussion, experiments show that the concentration of water (from 20 to $250 \mathrm{ppm}$ ) did not strongly impact the selectivity of the reaction. ${ }^{13}$ 
In conclusion, we followed an elaborated computational protocol to model metal-ionic liquid interfaces at the DFT level. Particularly, we designed a $\mathrm{Ru}(0001)$ surface in contact with 8 pairs of $\left[\mathrm{C}_{4} \mathrm{C}_{1}\right.$ pyrr] [FAP]. We used the resulting model to study the key rate and selectivity determining $\mathrm{N}_{2} \mathrm{H}$ intermediate in the NRR compared to the HER involved in the electrochemical synthesis of ammonia at room temperature. Our results indicate that interactions between $\mathrm{Ru}-\mathrm{N}_{2} \mathrm{H}$ species and $\mathrm{F}$ atoms of the $[\mathrm{FAP}]^{-}$anion increase activity and boost selectivity toward ammonia. Such fully atomistic computational approach holds promise to unravel new mechanistic features and guide the rational design of novel electrocatalytic interfaces for ammonia synthesis.

\section{ASSOCIATED CONTENT}

\section{S Supporting Information}

Computational details, radial distribution functions, intermediates, energies (PDF)

Cartesian coordinates (XYZ)

\section{AUTHOR INFORMATION}

\section{Corresponding Authors}

*E-mail: mortuno@iciq.es.

*E-mail:nlopez@iciq.es.

\section{ORCID}

Manuel A. Ortuño: 0000-0002-6175-3941

Oldamur Hollóczki: 0000-0003-3105-7176

Barbara Kirchner: 0000-0001-8843-7132

Núria López: 0000-0001-9150-5941

\section{Notes}

The authors declare no competing financial interest.

\section{ACKNOWLEDGMENTS}

M.A.O. and N.L. acknowledge MINECO (CTQ2015-68770) and "Juan de la Cierva-Incorporación" postdoctoral program (IJCI-2016-29762) for financial support. The work has been peformed under the Project HPC-EUROPA3 (INFRAIA2016-1-730897), with the support of the EC Research Innovation Action under the H2020 Programme. M.A.O. gratefully acknowledges the computer resources (Cray XC40 Hazel Hen) and technical support provided by HLRSStuttgart. M.A.O. also acknowledges the computer resources at Caesaraugusta and technical support provided by BIFIUniversity of Zaragoza (RES-QCM-2018-3-0005).

\section{REFERENCES}

(1) Erisman, J. W.; Sutton, M. A.; Galloway, J.; Klimont, Z.; Winiwarter, W. How a Century of Ammonia Synthesis Changed the World. Nat. Geosci. 2008, 1, 636-639.

(2) Foster, S. L.; Perez Bakovic, S. I.; Duda, R. D.; Maheshwari, S.; Milton, R. D.; Minteer, S. D.; Janik, M. J.; Renner, J. N.; Greenlee, L. F. Catalysts for Nitrogen Reduction to Ammonia. Nat. Catal. 2018, 1, $490-500$.

(3) Martín, A. J.; Shinagawa, T.; Pérez-Ramírez, J. Electrocatalytic Reduction of Nitrogen: From Haber-Bosch to Ammonia Artificial Leaf. Chem. 2018, DOI: 10.1016/j.chempr.2018.10.010.

(4) Guo, C.; Ran, J.; Vasileff, A.; Qiao, S.-Z. Rational Design of Electrocatalysts and Photo(electro)catalysts for Nitrogen Reduction to Ammonia $\left(\mathrm{NH}_{3}\right)$ under Ambient Conditions. Energy Environ. Sci. 2018, 11, 45-56.

(5) Deng, J.; Iñiguez, J. A.; Liu, C. Electrocatalytic Nitrogen Reduction at Low Temperature. Joule 2018, 2, 846-856.

(6) Cui, X.; Tang, C.; Zhang, Q. A Review of Electrocatalytic Reduction of Dinitrogen to Ammonia under Ambient Conditions. Adv. Energy Mater. 2018, 8, 1800369.

(7) Singh, A. R.; Rohr, B. A.; Schwalbe, J. A.; Cargnello, M.; Chan, K.; Jaramillo, T. F.; Chorkendorff, I.; Nørskov, J. K. Electrochemical Ammonia Synthesis-The Selectivity Challenge. ACS Catal. 2017, 7, 706-709.

(8) Montoya, J. H.; Tsai, C.; Vojvodic, A.; Nørskov, J. K. The Challenge of Electrochemical Ammonia Synthesis: A New Perspective on the Role of Nitrogen Scaling Relations. ChemSusChem 2015, 8, 2180-2186.

(9) Singh, A. R.; Montoya, J. H.; Rohr, B. A.; Tsai, C.; Vojvodic, A.; Nørskov, J. K. Computational Design of Active Site Structures with Improved Transition-State Scaling for Ammonia Synthesis. ACS Catal. 2018, 8, 4017-4024.

(10) Licht, S.; Cui, B.; Wang, B.; Li, F.-F.; Lau, J.; Liu, S. Ammonia Synthesis by $\mathrm{N}_{2}$ and Steam Electrolysis in Molten Hydroxide Suspensions of Nanoscale $\mathrm{Fe}_{2} \mathrm{O}_{3}$. Science 2014, 345, 637-640.

(11) Li, S.-J.; Bao, D.; Shi, M.-M.; Wulan, B.-R.; Yan, J.-M.; Jiang, Q. Amorphizing of Au Nanoparticles by $\mathrm{CeO}_{x}-\mathrm{RGO}$ Hybrid Support towards Highly Efficient Electrocatalyst for $\mathrm{N}_{2}$ Reduction under Ambient Conditions. Adv. Mater. 2017, 29, 1700001.

(12) Suryanto, B. H. R.; Kang, C. S. M.; Wang, D.; Xiao, C.; Zhou, F.; Azofra, L. M.; Cavallo, L.; Zhang, X.; MacFarlane, D. R. Rational Electrode-Electrolyte Design for Efficient Ammonia Electrosynthesis under Ambient Conditions. ACS Energy Lett. 2018, 3, 1219-1224.

(13) Zhou, F.; Azofra, L. M.; Ali, M.; Kar, M.; Simonov, A. N.; McDonnell-Worth, C.; Sun, C.; Zhang, X.; MacFarlane, D. R. Electrosynthesis of Ammonia from Nitrogen at Ambient Temperature and Pressure in Ionic Liquids. Energy Environ. Sci. 2017, 10, 2516-2520.

(14) Stevanovic, S.; Costa Gomes, M. F. Solubility of Carbon Dioxide, Nitrous Oxide, Ethane, and Nitrogen in 1-Butyl-1methylpyrrolidinium and Trihexyl(tetradecyl)phosphonium Tris(pentafluoroethyl)-trifluorophosphate (eFAP) Ionic Liquids. J. Chem. Thermodyn. 2013, 59, 65-71.

(15) Honkala, K.; Hellman, A.; Remediakis, I. N.; Logadottir, A.; Carlsson, A.; Dahl, S.; Christensen, C. H.; Nørskov, J. K. Ammonia Synthesis from First-Principles Calculations. Science 2005, 307, 555558.

(16) Rotenberg, B.; Salanne, M. Structural Transitions at Ionic Liquid Interfaces. J. Phys. Chem. Lett. 2015, 6, 4978-4985.

(17) Hellman, A.; Honkala, K.; Remediakis, I. N.; Logadóttir, A.; Carlsson, A.; Dahl, S.; Christensen, C. H.; Nørskov, J. K. Ammonia Synthesis and Decomposition on a Ru-Based Catalyst Modeled by First-Principles. Surf. Sci. 2009, 603, 1731-1739.

(18) Kirchner, B.; Hollóczki, O.; Canongia Lopes, J. N.; Pádua, A. A. H. Multiresolution Calculation of Ionic Liquids. WIREs Comput. Mol. Sci. 2015, 5, 202-214.

(19) Buchner, F.; Forster-Tonigold, K.; Bozorgchenani, M.; Gross, A.; Behm, R. J. Interaction of a Self-Assembled Ionic Liquid Layer with Graphite(0001): A Combined Experimental and Theoretical Study. J. Phys. Chem. Lett. 2016, 7, 226-233.

(20) Weber, H.; Kirchner, B. Ionic Liquid Induced Band Shift of Titanium Dioxide. ChemSusChem 2016, 9, 2505-2514.

(21) Pensado, A. S.; Pádua, A. A. H. Solvation and Stabilization of Metallic Nanoparticles in Ionic Liquids. Angew. Chem., Int. Ed. 2011, 50, 8683-8687.

(22) Jha, K. C.; Liu, H.; Bockstaller, M. R.; Heinz, H. Facet Recognition and Molecular Ordering of Ionic Liquids on Metal Surfaces. J. Phys. Chem. C 2013, 117, 25969-25981.

(23) Paredes, X.; Fernández, J.; Pádua, A. A. H.; Malfreyt, P.; Malberg, F.; Kirchner, B.; Pensado, A. S. Bulk and Liquid-Vapor Interface of Pyrrolidinium-Based Ionic Liquids: A Molecular Simulation Study. J. Phys. Chem. B 2014, 118, 731-742. 
(24) Bellarosa, L.; García-Muelas, R.; Revilla-López, G.; López, N. Diversity at the Water-Metal Interface: Metal, Water Thickness, and Confinement Effects. ACS Cent. Sci. 2016, 2, 109-116.

(25) Skulason, E.; Bligaard, T.; Gudmundsdottir, S.; Studt, F.; Rossmeisl, J.; Abild-Pedersen, F.; Vegge, T.; Jonsson, H.; Nørskov, J. K. A Theoretical Evaluation of Possible Transition Metal Electrocatalysts for $\mathrm{N}_{2}$ Reduction. Phys. Chem. Chem. Phys. 2012, 14, 12351245.

(26) Back, S.; Jung, Y. On the Mechanism of Electrochemical Ammonia Synthesis on the Ru Catalyst. Phys. Chem. Chem. Phys. 2016, 18, 9161-9166.

(27) Wang, D.; Azofra, L. M.; Harb, M.; Cavallo, L.; Zhang, X.; Suryanto, B. H. R.; MacFarlane, D. R. Energy-Efficient Nitrogen Reduction to Ammonia at Low Overpotential in Aqueous Electrolyte under Ambient Conditions. ChemSusChem 2018, 11, 3416-3422.

(28) Yao, Y.; Zhu, S.; Wang, H.; Li, H.; Shao, M. A Spectroscopic Study on the Nitrogen Electrochemical Reduction Reaction on Gold and Platinum Surfaces. J. Am. Chem. Soc. 2018, 140, 1496-1501.

(29) Dalvit, C.; Invernizzi, C.; Vulpetti, A. Fluorine as a HydrogenBond Acceptor: Experimental Evidence and Computational Calculations. Chem. - Eur. J. 2014, 20, 11058-11068.

(30) Choksi, T.; Majumdar, P.; Greeley, J. P. Electrostatic Origins of Linear Scaling Relationships at Bifunctional Metal/Oxide Interfaces: A Case Study of Au Nanoparticles on Doped MgO Substrates. Angew. Chem., Int. Ed. 2018, 57, 15410-15414.

(31) Aragonés, A. C.; Haworth, N. L.; Darwish, N.; Ciampi, S.; Bloomfield, N. J.; Wallace, G. G.; Diez-Perez, I.; Coote, M. L. Electrostatic Catalysis of a Diels-Alder Reaction. Nature 2016, 531, $88-91$.

(32) Zhang, L.; Vogel, Y. B.; Noble, B. B.; Gonçales, V. R.; Darwish, N.; Le Brun, A.; Gooding, J. J.; Wallace, G. G.; Coote, M. L.; Ciampi, S. TEMPO Monolayers on $\mathrm{Si}(100)$ Electrodes: Electrostatic Effects by the Electrolyte and Semiconductor Space-Charge on the Electroactivity of a Persistent Radical. J. Am. Chem. Soc. 2016, 138, 9611-9619.

(33) Hollóczki, O.; Berkessel, A.; Mars, J.; Mezger, M.; Wiebe, A.; Waldvogel, S. R.; Kirchner, B. The Catalytic Effect of Fluoroalcohol Mixtures Depends on Domain Formation. ACS Catal. 2017, 7, 18461852. 